\title{
İki Kere Özel Öğrenciler: Öğrenme Güçlüğü Olan Üstün Yetenekliler
}

\author{
AHMET BILDIREN \\ TAHSIN FIRAT
}

Özet

Çok küu̧ük yaştan itibaren farklı düşünceler, projeler. Ancak okul yaşamında başarısızlıklar. Yeteneğin ve zorluğun arasında sıkışmış bir çocuk nasıl tanılanmalı? Bu durum sadece zeka testleri ile anlaşılabilir mi? Bu araştırmada, bu sorulara cevap verebilmek için öğrenme güçlüğü olan üstün yetenekli öğrencilerin özelliklerinin ve tanılanmasının açıklanması amaçlanmıştır. Bu amaç doğrultusunda üstün yetenek, öğrenme güçlüğü kavramları öncelikle ele alınmış, ardından öğrenme güçlüğü olan üstün yetenekli öğrencilerin özellikleri ve tanılanması, ulusal ve uluslararası alan yazınla birlikte açıklanmıştır. Üstün yeteneklerin ve güçlüklerin bir araya gelerek oluşturduğu bu farklı öğrencilerin doğru tanılanması ve yönlendirilmesi için ilgili çalışmalarla beraber Türkiye'de yapılması gerekenler son bölümde tartışılmıştır.

Anahtar kelimeler: Öğrenme güçlüğü, üstün yetenek, iki kere özel

\author{
Abstract \\ - ARASTIRMA MAKALESI- \\ AHMET BILDIREN, ahmetbildiren@gmail.com \\ Aydın Adnan Menderes Üniversitesi, Eğitim Fakültesi, Özel Eğitim Bölümü \\ ORCID: https://orcid.org/0000-0003-3021-4299 \\ TAHSIN FIRAT, tahsinfirat02@gmail.com \\ Adıyaman Üniversitesi, Eğitim Fakültesi \\ ORCID: https://orcid.org/0000-0002-3577-7907

Different thoughts and projects from a very young age. But failures in school life. How to identification a child caught between your talent and difficulty? Can this 
situation be understood only with intelligence tests? In this study, it is aimed to explain the characteristics and identification of gifted students with learning disability in order to answer these questions. In line with this purpose, the concepts of giftedness and learning disability were first addressed, and then the characteristics and identification of gifted students with learning disability were explained together with national and international literature. In the last section, for gifted children with learning disability, to correct identification and referral needs to be done together with literature in Turkey were discussed.

Keywords: Learning disability, giftedness, twice exceptional

\section{Giriş}

Eğitim ortamlarında her öğrenci özeldir, fakat bazı öğrenciler var ki bunlar iki defa özeldir. Bu durumun çarpıcı örneklerinden biri üstün yetenekli öğrencilerde görülebilmektedir. Üstün yeteneğe başka bir özel gereksinim durumu eşlik ettiğinde, bu öğrencilere iki defa farklı olan öğrenciler (Twice Exceptional) denilmektedir (Reis, Baum ve Burke, 2014). Üstün yetenek ile duygu bozukluğu, dikkat eksikliği ve hiperaktivite, otizm ve öğrenme güçlükleri birlikte görülebilmektedir (Foley Nicpon, Allmon, Sieck ve Stinson, 2011; Neihart, 2008). Diğer taraftan, alan yazında iki defa farklı olma kavramının daha çok öğrenme güçlüğü olan üstünleri çağrıştırdığ1 belirtilmektedir (Baldwin, Omdal ve Pereles, 2015; Bianco ve Leech, 2010). Mevcut çalışmada, öğrenme güçlügü olan üstün yetenekliler ele alınacaktır. Bu doğrultuda, öğrenme güçlüğü olan üstün yetenekli öğrencilerin özellikleri ve tanılanma süreçleri incelenmiştir. Ayrıca, bilindiği üzere üstün yetenekli öğrencilerin ve öğrenme güçlüğü olan öğrencilerin farklı özellikleri ve ihtiyaçları vardır. Bu iki özel gereksinim grubunun birleşerek oluşturduğu öğrenme güçlüğü olan üstün yetenekli öğrencilerin de farklı ihtiyaçları olacaktır. Bu durum oldukça kafa karıştırıcı olabilmektedir (King, 2005). Bu öğrencilerin benzersiz ihtiyaçlarının yeterince karşılanması için öncelikle hem üstün yeteneklerin hem de öğrenme güçlüklerinin doğru bir şekilde tanımlanması gerekmektedir (Sansom, 2015).

\section{Üstün Yetenekli Öğrenciler}

Üstün yetenek kavramı geçmişte tek boyutta açıklanırken, günümüzde çok boyutlu bir kavram haline gelmiştir. Araştırmacılar, başlangıçta üstün 2020/2 yeteneği genetik bileşenlerle eşleştirirken, son 40 yılda yapılan çalışmalarla birlikte üstün yetenek tanımını genişletmişlerdir. Renzulli (2005) üçlü 
halka modeliyle üstün yeteneği; ortalamanın üstünde yetenek, yaratıcılık ve işe adanmışlık boyutlarının kesişimi doğrultusunda açıklamıştır. Gardner (2011) çoklu zeka kuramında 9 farklı başlıkta (sözel, mantıksalmatematiksel, uzamsal, müziksel, bedensel, sosyal, içsel, doğa ve varoluşçu zekâ) ele almıştır. Francoys Gagne de (2003) çocukların üstün yetenekli statüsünde olabilmesinin davranışlarından anlaşılabileceğini ve çocuklardaki potansiyelle ilgilenilmesi gerektiğini ortaya koymuştur. Gagne, modeline etki yapan beş bileşen: Şans, bahşedilmiş yetenek, içsellik, öğrenme/ uygulama ve çevredir.

Abraham Tannenbaum'un (2003) yıldız modelinde de üstün yetenek kavramı çok boyutlu olarak ele alınmıştır. Üstün yeteneğin birbiriyle etkileşimi olan beş farklı psikolojik ve sosyal etkene bağlı olmasını önermiştir. Tannenbaum (2003)'e göre üstün yetenekte genel zihinsel yeteneğin büyük bir önemi vardır ve üstün yetenekli değerlendirme için ortalama üstü bir genel zihinsel yetenek gerekir. Bununla birlikte erken yaştan itibaren gözlemlenebilen özel yetenekler söz konusudur. Genel zihinsel yetenek ile etkileşimde bu yetenekler, belli bir yetenek alanının üstüne çıkmaktadır. Kişilerarası beceriler, motivasyon, azim ve öz güven kişisel özellikler olarak modelin bir başka alanını oluşturmaktadır. Genetik faktörlere bağlı olarak bir alandaki yaratıcı özellikler ve çevresel uyarıcılar, dışsal bir bağlam olarak üstün yeteneği şekillendirmektedir. Bu 4 boyuta ek olarak Tannenbaum son olarak yeteneğin ortaya çıkmasındaki şans faktörünü ortaya koymaktadır. Yeteneğin ortaya çıkması için bireyin o ortamla tanışmış olması ve doğru yönlendirilmesi gerekmektedir. Bu beş farklı faktörde ele alındığında üstün yeteneğin kapsamlı bir şekilde açıklandığı söylenebilir.

Farklı yaklaşımlar farklı tanımlamalar ortaya çıkarsa da üstün yetenekli çocukların ortak olarak sergiledikleri genel özelliklerinden bahsedilebilir (Sak, 2017). Üstün yetenekli çocuklar, akranlarından farklı düşünür ve davranır, bu farklılıklar çocukların gelişiminin erken aşamalarında gözlemlenebilir (Gross, 2003). Wright ve Ford'un (2017) Amerikan Üstün Yetenekli Çocuklar Derneği çalışmasından uyarladığı çalışmada üstün yetenekli çocukların dil ve öğrenme, psikomotor gelişim, motivasyon ve kişisel özellikler alanında diğer çocuklara göre farklılıklar gösterdiğini ifade edilmektedir (Tablo 1). Türkiye'de yapılan bir çalışmada da aile gözlemine göre, 0-2 yaş döneminde üstün yetenekli çocukların tipik gelişim gösteren çocuklara göre daha farklı kelimeleri yerinde ve doğru bir şekilde kullandıkları, geniş bir kelime hazinesine sahip oldukları ve söylenenleri çok erken dönemde algılayıp, istenilen şeyleri yaptıkları tespit edilmiştir. 2-4 yaş döneminde ise üstün yetenekli çocukların algılamalarının çok iyi olduğu, 
hızlı problem çözdükleri, erken okuma, bilgisayar kullanma, soyut düşünme gibi özellikler sergiledikleri tespit edilmiştir (Bildiren, 2018a).

Tablo 1. Okul öncesi dönemindeki üstün yetenekli çocukların özellikleri

\begin{tabular}{ll}
\hline Dil ve öğrenme & Erken konuşma \\
& Erken okuma \\
& Geniş kelime hazinesi \\
& Özellikle tartışmada kendini ifade etmekten hoşlanma \\
& Çizim, müzik veya diğer sanatlarda ileri düzeyde performans \\
\hline Psikomotor gelişim & Erken yürüme \\
ve motivasyon & Bir şeyleri yazma, renklendirme ve yapımında erken gelişim \\
& Gelişmiş ince motor beceriler \\
& Sorgulama gerektiren projelerden hoşlanma \\
& Keşfetme isteği \\
& Merak ve her şeyin nedenini sorgulama \\
& Aktiflik \\
& Hedefe odaklanma \\
& Yetişkinlerle zaman geçirmeyi tercih etme \\
& Kendi kendini yönetme \\
& Bağımsız çalışma \\
& Ölüm, savaş ve dünyadaki açlık gibi konularda farkındalık \\
& gösterme
\end{tabular}

Araştırmalar ayrıca gelişimlerinin eşzamansız olduğunu da ortaya koymaktadır (Morelock, 1992). Bilişsel gelişimleri daha hızlı iken (Walsh, Hodge, Bowes ve Kemp, 2010), sosyal ve duygusal alanlarda asenkron gelişim gösterebilirler (Daniels ve Piechowski 2009), psikomotor gelişimleri akranlarından daha yavaş olabilir (Alsop 2003). Aşırı heyacanlı (Tieso 2007), hareketli, yüksek enerji düzeyine sahip, analiz sentez yapan, yoğun entelektüel uyarım gerektiren bireyler olarak karşımıza çıkarlar (Daniels ve Piechowski 2009; Piechowski ve Chucker 2011).

Üstün yetenekli çocukların, yetenekli olmayan akranlarına göre bilgiyi daha verimli bir şekilde aktardıkları varsayılır (Klavir ve Gorodetsky, 2001). Özellikle zorlu transfer görevlerinde üstün yetenekli çocukların üstün yetenekli olmayan akranlarından daha iyi performans gösterdikleri görülmüştür (Geake, 2008). Yeni stratejiler öğrendikten sonra, üstün yetenekli öğrencilerin bu stratejileri kendiliğinden yeni öğrenme bağlamlarına aktardıkları ortaya konmaktadır (Kanevsky, 1990). Üstün yetenek kavramının, yüksek IQ ve gelişmiş yönetici işlevlerinin olağanüstü 
yaratıcılık ve daha yüksek motivasyonla kombinasyonu ile tanımlanması (Navas-Sánchez vd., 2016), bu özelliklerin ortaya çıkmasını sağlamış olabilir. Üstün yetenekli çocuklar, muhtemelen nörofizyolojik farklılıklar nedeniyle daha hızlı ve daha etkili bir şekilde öğrenirler (Gross 2006). Beyinlerinin farklı alanları arasında, özellikle korpus kallozum boyunca hemisferler arasında ve prefrontal ve parietal ilişkisel alanlar arasında daha fazla bağlantıya sahiptirler (Navas-Sánchez vd., 2014). Bunu destekleyen araştırmalarda (Zhang, Gan ve Wang, 2017), üstün yetenekli ergenlerin beyinlerinin daha hızlı olgunlaştığı tespit edilmiştir.

\section{Öğrenme Güçlüğü Olan Öğrenciler}

Samuel Kirk 1960’lı yılların başında “Öğrenme Güçlüğü” kavramını ilk kez kullanırken, bu kavramın günümüzde bu kadar popüler hale geleceğini kestirmiş miydi bilinmez ama geçen yaklaşık 60 yıllık süreçte öğrenme güçlügüüün özel eğitim alanında en sık duyulan kavramlardan biri haline geldiğini söylememiz mümkündür (Fırat ve Koçak, 2018). Amerika Birleşik Devletleri'nde en son çıkan raporlardan birinde, Engelli Bireyler Eğitim Yasası (The Individuals with Disabilities Education Act; IDEA) kapsaminda özel eğitim hizmetleri alan 3-21 yaş arası öğrenci sayısının 7 milyon olduğu ve bu öğrencilerin yüzde 34'ünün öğrenme güçlükleri olan öğrencilerden oluştuğu belirtilmiştir (McFarland vd., 2019). Öğrenme güçlüğü olan öğrencilerin eğitim ortamlarında sayılarının bu kadar fazla olması, öğrenme güçlüğünün nasıl tanımlanacağı, öğrenme güçlüğü olan öğrencilerin nasıl tanılanacağı ve eğitimlerinin nasıl olacağı konusunda da tartışmaları beraberinde getirmektedir.

Yaygın olarak kabul gören tanımlardan birisi olan Engelli Bireylerin Eğitim Yasası'nda (IDEA, 2004) öğrenme güçlüğü, yazılı ve sözlü dili anlama ve kullanmada temel olan bir veya daha fazla psikolojik sürecin etkilenmesiyle ortaya çıan dinleme, düşünme, konuşma, okuma yazma ve matematiksel hesaplamalar yapmadaki güçlükler olarak tanımlanmaktadır. Tanımda, öğrenme güçlügüüün algısal güçlükleri, beyin zedelenmesini, beyindeki minimal düzeydeki işlev bozukluğunu, disleksiyi ve gelişimsel dil bozukluklarını içerdiği ancak görsel, işitsel ve motor bozukluklardan, zihinsel yetersizlikten, duygusal bozukluklardan, çevresel, kültürel ve ekonomik olumsuzluklardan kaynaklanan öğrenme güçlüklerini içermediği ifade edilmektedir. Böylesine geniş kapsamlı bir tanım çerçevesinde ele alınan öğrenme güçlüğü olan öğrencilerin birbirinden farklı özelliklere sahip olmaları muhtemeldir. Nitekim ilgili alanyazında, öğrenme güçlüğü olan öğrencilerin heterojen bir grup olduğu vurgulanmaktadır (Fletcher, Lyon, 
Fuchs ve Barnes, 2018; Fuchs ve Fuchs, 2001; Pierangelo ve Giuliani, 2008; Swanson, Harris ve Graham, 2013; Wong ve Butter, 2012).

Öğrenme güçlüğü olan öğrencilerin temel özelliklerine bakıldığında, bu öğrencilerin okuma, yazma ve matematik gibi temel akademik becerilerde güçlük yaşadıkları ifade edilmektedir (American Psychiatric Association, 2013; Berninger ve Swanson, 2013). Bunların yanında motivasyonlarının (Melekoglu, 2011; Sideridis, Morgan, Botsas, Padeliadu ve Fuchs, 2006; Zisimopoulos ve Galanaki, 2009) ve belleklerinin zayıf olduğu (Cornoldi, Giofre, Orsini ve Pezzuti, 2014; McNamara ve Wong, 2003; Watson, Gable ve Morin, 2016), sosyal becerilerde güçlük yaşadıkları (Fırat, 2020; Forness ve Kavale, 1996; Kavale ve Mostert, 2004), strateji kullanmada sorun yaşadıkları (Boyle, Rosen ve Forchelli, 2016; Fırat ve Koçak, 2019; Heiman ve Precel, 2003), çeşitli davranışsal problemlere sahip oldukları (hiperaktivite gibi) (Çakıroğlu, 2017; Mayes ve Calhoun, 2006; Pastor ve Reuben, 2008) ve duygusal problemlerin de (Bryan, Burstein ve Ergul, 2004; Handwerk ve Marshall, 1998; Huntington ve Bender, 1993) görülebildiği vurgulanmaktadır.

Öğrenme güçlüğü olan öğrencilerin tanılamasında çoğunlukla yaşadıkları bu güçlükler çerçevesinde tanı kriterlerini sağlayıp sağlamadıklarına bakılmaktadır. Oysaki öğrenme güçlüğünün tanımında yer alan önemli unsurlardan birisi de öğrenme güçlüğüne sahip öğrencilerin zekalarının normal ve üstün olmasıdır (Büttner ve Hasselhorn, 2011). Bu özellik öğrenme güçlüğü olan öğrencilerin yaşadıkları sorunların zihinsel yetersizlikten değil, bellek, bilgiyi işlemleme yani daha çok bilişsel süreçlerdeki bozukluklardan kaynaklı olduğunu göstermektedir (Cornoldi vd., 2014). Aynı zamanda öğrenme güçlüğü olan öğrencilerin zekalarının normalin üstünde olabilmesi, bu öğrencilerin bazılarının üstün yetenekli olabileceğini de göstermektedir (Park, 2010).

\section{Öğrenme Güiçliuğui Olan Üstünler}

İki kere farklı öğrenciler olarak da bilinen öğrenme güçlüğü olan üstün yetenekli öğrencilerle ilgili sorulması gereken pek çok soru olabilir. Akla ilk gelen ise: "Üstün yetenekli bir öğrenci öğrenme güçlüğü yaşayabilir mi?" olmaktadır. Aslında, güçlü ve zayıf yönleri birbiriyle ilgisiz alanlarda olan öğrenme güçlügü olan üstünler, akademik alanlarda en çok yanlış anlaşılan, yetersiz hizmet alan ve özel eğitim hizmetlerine ihtiyaç duyan öğrencilerdir (Brody ve Mills, 1997). Sınıfta bu bireyler bazen hayalperest ya da etkinliklere katılmayan, düzensiz, ilgisiz, güçsüz, öğrenemeyen öğrenciler olarak algılanmaktadır (Dole, 1999). Robinson (1999) bu öğrencileri şu şekilde açıklamaktadır: 
Bazı öğrenciler kafa karıştırıcı bir dizi öğrenme özelliği sunar. Kötü organizasyon becerilerine sahip olabilirler, sınıfta dikkatsiz olabilirler, temel yazım veya okuma becerilerini geliştiremeyebilirler, akran ilişkileri zayıf olabilir ve öz saygıları düşük olabilir, okuldan hoşlanmayabilirler veya okul başarısızlığı sergileyebilirler. Aynı zamanda, mükemmel bir kelime dağarcığına sahip olabilirler, olağanüstü analitik ve kavrama becerileri sergileyebilirler, belirli bir alanda olağanüstü ilgi veya yetenek gösterebilir veya karmaşık problem çözme becerileri kullanabilirler.

Bu öğrenciler, bir veya daha fazla alanda üstün yetenek ve aynı zamanda bir veya daha fazla akademik alanda öğrenme güçlükleri gösterirler (Foley Nicpon ve Assouline, 2020). Güçlü yönler üstün yeteneğe atfedilirken, zayıf yönler ise öğrenme güçlüklerine atfedilir (Baum 1990). Reis vd. (2014) bu üstün yeteneklerin ve güçlüklerin bir araya gelerek, "benzersiz" bir öğrenci grubu oluşturduğunu ifade etmiştir. Bir diğer ifade ile öğrenme güçlüğü olan üstün yetenekli öğrenciler, öğrenme güçlüğü olan ve normal gelişim gösteren öğrencilerden bilişsel, kişisel ve sosyal olarak önemli bir farklılık göstermektedir. Öğrenme güçlüğü olan üstün yetenekli öğrencilerin özelliklerini Ruban (2005) Tablo 2'de özetlemiştir. Ruban, öğretmenlerin öğrencilerle çalışırken her iki ortak özelliği de dikkate almalarını önermektedir.

Tablo 2. Öğrenme Güçlüğü Olan Üstün Yetenekli Öğrencilerin Özellikleri

\begin{tabular}{|c|c|}
\hline $\begin{array}{l}\text { Üstün Yetenekli Olmanın } \\
\text { Kimliğini Engelleyen } \\
\text { Özellikler }\end{array}$ & Karakteristik Güçlü Yönler \\
\hline $\begin{array}{l}\text { - Akademik başarısızlıktan } \\
\text { kaynaklı hayal kırıklığı }\end{array}$ & - Gelişmiş kelime kullanımı \\
\hline - Öğrenilmiş çaresizlik & - Olağanüstü analitik yetenekler \\
\hline - Genel motivasyon eksikliği & - Yüksek düzeyde yaratıcılık \\
\hline - Yıkıcı davranışlar & $\begin{array}{l}\text { - Yüksek üretkenlik seviyesi (özellikle ilgi } \\
\text { alanında) }\end{array}$ \\
\hline - Mükemmelliyetcilik & - Gelişmiş problem çözme becerileri \\
\hline $\begin{array}{l}\text { - Aşırı duyarlılık (örneğin } \\
\text { eleştiriye, duyguya } \\
\text { diğerleri) }\end{array}$ & - Farklı fikirler ve çözümler düşünme yeteneği \\
\hline - Görevleri tamamlayamama & - Özel yetenek (sanatsal, müzikal veya mekanik) \\
\hline $\begin{array}{l}\text { - Organizasyon becerileri } \\
\text { eksikliği }\end{array}$ & - Çok çeşitli ilgi alanları \\
\hline
\end{tabular}


- Dikkatsizlik

- Zayif dinleme ve konsantrasyon becerileri

- Bellek ve algisal yetenekleri görevlerde yetersizlik

- Düşük benlik saygısı

- Gerçekçi olmayan beklentiler

- Sosyal becerilerde zayıflık (örneğin, ilişkilerde saldırgan ve savunmacı olabilir)
- İyi bellek

- Güçlü eleştirel düşünme becerileri

- Aralarındaki ilişkileri görme konusunda olağandışı yetenek

- Fikirler ve kavramlar arasındaki karşılıklı ilişkileri görme konusunda sıra dışı yetenek

- Olağanüstü muhakeme becerileri

- Göreve adanmışlık

- Bilgi ve keşfetme arzusu

- Mizah anlayışı

- Çeşitli özel yetenekler

Van Viersen, Kroesbergen, Slot ve de Bree (2016) öğrenme güçlügü olan üstün yetenekli öğrencilerin fonolojik farkındalıkta, hızlı isimlendirmede zayıf olduklarını, kısa süreli bellek, çalışan bellek ve dil becerilerinde ise güçlü olduğunu ortaya çıkarmıştır. Ayrıca araştırma, fonolojinin, öğrenme güçlüğü olan üstün yetenekli çocuklar için bir risk faktörü olduğunu göstermiştir. Ancak bu, çalışan bellek, dilbilgisi ve kelime bilgisi gibi diğer beceriler tarafından hafifletilerek, bilişsel eksikliğin telafi edilmesine ve okuryazarlık zorluklarının maskelenmesine neden olmuştur.

Öğrenme güçlüğü olan üstün yetenekli öğrenciler genel olarak üç şekilde sınıflanmaktadır (Brody ve Mills, 1997). İlk grup, üstün yetenekli tanısı alan ancak öğrenme güçlüğü de olan öğrencilerdir. Bu grup, yüksek IQ veya yüksek başarı sergiledikleri için kolayca üstün yetenekli olarak tanımlanabilir (Bisland, 2004). Bu, bir anlamda üstün yeteneğin, öğrencinin yaşadığı güçlükleri maskelemesidir (Reis vd., 2014). İkinci grup, öğrenme güçlüğü tanısı alan, güçlüklerin potansiyellerini maskelemesiyle üstün yetenekleri belirlenemeyen öğrencilerden oluşur (Neihart, 2008). Yetersiz değerlendirme veya güçlüklerin daha düşük IQ puanlarına yol açma olasılığ nedeniyle, bu öğrencilerin üstün zekâsı genellikle gizli kalır (Beckmann ve Minnaert, 2018). Bu öğrenciler özel eğitime yönleridirler fakat üstün yeteneklerinin geliştirilebilmesi konusunda destek alamazlar (Neihart, 2008). Genellikle öğrencinin yaşadığı güçlük alanlarına yönelik öğrenciye bir destek verilir. Üçüncü grup ise üstünlük ve öğrenme güçlüğünün $2020 / 2$ birbirini maskelemesi sonucu herhangi bir tanı almayan öğrencilerdir (King, 2005). Bu öğrenciler ortalama bir öğrenci özelliği gösterdikleri 
için herhangi bir değerlendirmeye alınmayan, dolayısıyla IQ'leri ile performansları arasındaki farkın belirlenemediği öğrencilerdir (McCoach, Kehle, Bray ve Siegle, 2001).

\section{Öğrenme Güçliuğü Olan Üstün Yeteneklilerin Tanılanması}

Öğrenme güçlüğü olan üstün yeteneklilerin tanılanması eğitimciler ve araştırmacılar için zor bir durumdur. Bu güçlük nedeniyle öğrenme güçlüğü olan üstün yetenekliler yanlış tanılanma ve ihtiyaç duyduğu programdan yararlanamama riski altındadır (Ruban ve Reis, 2005). Bu riski ortadan kaldırmak için farklı tanılama yöntemleri önerilmektedir. Örneğin, Brody ve Mills (1997) bir çocuğu öğrenme güçlüğü olan bir üstün yetenekli olarak etiketleyip etiketlememeyi düşünürken üç faktörün özellikle önemli olduğu sonucuna varmıştır: olağanüstü yetenek kanıtı, yetenek-başarı tutarsızlığı ve bir işlemleme yetersizliği. Bu yaklaşım öğrenme güçlüğü olan üstün yeteneklilerde, yapılandırılmış görüşmeler, davranış gözlemleri, yaratıcılık testleri ve öğretmen adaylıkları gibi daha öznel endekslerle, IQ puanlarının entegrasyonu ile yapılan tanılamalara yol açmış oldu. McCoach, Kehle, Bray ve Siegle (2001) öğrenme güçlüğü tanısında kullanılan başarı ve zeka düzeyi arasındaki tutarsızlık yaklaşımının öğrenme güçlüğü olan üstün yetenekli çocuklar için de kullanılmasını ve tanı için IQ testlerinin, başarı testlerinin ve müfredata dayalı değerlendirmeler ve portfolyo incelemeleri gibi diğer araçların birlikte kullanılmasını önermektedirler. Nielsen (2002) tanı için Wechsler zeka ölçeğinin kodlama ve sayı dizisi alt testlerinde düşük puanların aranmasını önermiştir. Bununla birlikte profil analizleri, geniş üstün yeteneklilik tanımları ve öğrenme güçlüğünün başarı ve zeka düzeyi arasındaki tutarsızlık yaklaşımı ile birlikte tanının konmasını öne sürmüştür. Silverman (2003) ise üstün yeteneğin ve öğrenme güçlügünün birbirlerini çeşitli şekillerde maskeleyebileceğinden ayrı alt test puanlarının incelenmesinin zorunlu olduğunu savunmuştur. Ayrıca, dikkat sorunları, öğrenme stilleri ve kaygı gibi ek koşulların test performansını etkileyebileceğini ve farklı testler ve alt testler arasındaki farklılıkları yorumlarken dikkate alınması gerektiğini belirtmiştir. Araştırmacıların savundukları öneriler dikkate alındığında özel eğitimin her aşamasında olduğu gibi öğrenme güçlüğü olan üstün yetenekli öğrenciler için de formal ve informal değerlendirmeye dayalı çoklu değerlendirme yaklaşımının daha doğru bilgi vereceği söylenebilir.

Öğrenme güçlüğü olan öğrencilerin gerek tanılama gerekse müdahale yaklaşımında kullanılan (Berninger, 2006; Kavale ve Spaulding, 2008) 
müdahaleye tepki yönteminin son yıllarda öğrenme güçlügü olan üstün yetenekli öğrencilerin tanılamasında da uygulanması önerilmektedir (McCallum vd., 2013; Yssel, Adams, Clark ve Jones, 2014). Başarısızlık ve zeka düzeyi arasındaki tutarsızlığın ortaya çıkarılması için ciddi bir süre geçmektedir (Vaughn, Linan-Thompson ve Hickman, 2003). Bu durumu engellemek için müdahaleye tepki yöntemi kullanılması başarısızlık için beklemeyi ortadan kaldırmaktadır. Bu yönteme göre ilk aşamada, tüm öğrenciler yüksek kaliteli eğitim alır ve tarama değerlendirmelerini tamamlar. Taramalarda kötü performans gösteren veya beklenen hızda öğrenmeyen öğrenciler, Kademe 2 ve Kademe 3 müdahalelerde daha yoğun eğitim alırlar. Tipik olarak, öğrenciler Kademe 3 müdahalelerine cevap vermez ise, öğrenme güçlüğünün öğrenme yeteneklerine etki edip etmediğini belirlemek için değerlendirmeye yönlendirilirler. Son araştırma bulguları, tutarsızlık modelinin müdahaleye tepki çerçevesi içinde öğrenme güçlüğü olan üstün yetenekli öğrenciler için taramaya yardımcı olabileceğini düşündürmektedir (McCallum vd., 2013; Yssel, Adams, Clarke ve Jones, 2014).

Birçok makale öğrenme güçlüğü olan üstün yeteneklileri tanılama yaklaşımlarını savunsa da (Baum ve Novak, 2010; Coleman, 2005), standartlaştırılmış bir tanımlama sürecinin olmaması, okulların bu öğrencileri tanılayamamasına ve bu öğrencilerin ihtiyacına uygun eğitim alamamasına yol açmaktadır. Bu nedenle, öğrenme güçlügü olan üstün yetenekli öğrencileri tanımlamak için modelleri birleştirmek uygun olabilir, çünkü bu öğrencilerin öğrenme güçlüğü ile ilgili temel bilişsel eksikliklere sahip oldukları ve genellikle mutlak yerine göreli akademik açıklar sergiledikleri savunulur (Assouline vd., 2010; Lovett ve Sparks, 2013).

\section{Tiirkiye'de Öğrenme Güçlüğüi Olan Üstünler}

Türkiye'de son 20 yılda özel eğitim alanında önemli gelişmelerin olduğunu söylememiz mümkündür. İlk ulusal zeka testi olan Anadolu-Sak'ın hazırlanması ve hali hazırda uygulanıyor olması, özel eğitim alanındaki akademisyenlerin ve üniversitelerdeki özel eğitim bölümlerinin sayısındaki artış buna örnek verilebilir. Yine son yıllarda Ankara Üniversitesindeki akademisyenler tarafından Erken Okur Yazarlık Testi'nin (EROT), Hızlı İsimlendirme Testi ve Çalışma Belleği Ölçeğinin hazırlanması öğrenme güçlügü olan öğrencilerin tanılanmasında önemli adımlar olarak ele alınabilir. Türkiye'de üstün yetenekli öğrencilerin tanılanmasında belirli bir ilerleme kaydedilmektedir. Diğer taraftan, öğrenme güçlüğü olan öğrencilerin tanılanması ve eğitimleri ile ilgili ciddi sorunlar bulunmaktadır 
(Melekoğlu; 2017; Özmen, 2008). Bu durumun öğrenme güçlüğü olan üstün yetenekli öğrenciler için de söz konusu olduğunu söylememiz mümkündür. Çarpıcı bir diğer durum ise öğrenme güçlüğü olan üstünlere yönelik az ve sınırlı sayıda çalışmanın olmasıdır. Fırat (2019) okul öncesi öğretmenlerinin öğrenme güçlüğü olan üstün yetenekli öğrenciler hakkında sınırlı bilgiye sahip olduklarını ve bu bilgilerinin oldukça yüzeysel olduğunu belirlemiştir. Araştırmada, katılımcıların yarısına yakınının öğrenme güçlüğü ile üstün yeteneğin birlikte aynı çocukta görülemeyeceği düşüncesine sahip olduğu tespit edilmiştir. Bildiren ve Furat (2020) yaptıkları çalışmada öğrenme güçlüğü olan üstün yetenekli öğrencilerin tanılaması ile ilgili çeşitli problemlerin olduğunu, bu çocukların sadece IQ testleri ile değerlendirilmesinin yeterli olmadığını belirtmişlerdir. Bu çalışmada sadece zeka testi ile dikkat dağınıklığı tanısı konulan bir çocuğun çoklu değerlendirme ile öğrenme güçlüğü olan üstün yetenekli olduğunu kanıtlamışlardır. Araştırmacılar ayrıca, öğrenme güçlüğü olan üstün yetenekli öğrencilerin erken tanılanması gerektiğine dikkat çekerek, öğrenci performansının aile, öğretmen ve öğrenci ile ilgilenenler tarafından iyi gözlemlenmesi gerektiğini vurgulamışlardır.

\section{TARTIŞMA}

Öğrenme güçlügüu olan bir öğrenci, akademik başarının bir yönüne etki eden belirli bir öğrenme yetersizliğiyle birlikte var olan gelişmiş entelektüel yeteneklere sahiptir (Foley Nicpon ve Assouline, 2020). Ancak bu yetenekler ve güçlük çekilen alanlar her zaman belirlenememektedirler. Robinson (1999)'a göre öğrenme güçlüğü alanındaki eğitim profesyonellerinin çoğu, güçlü yönlerin nasıl tanımlanacağı ve geliştirileceği konusunda bilgiden yoksundur ve üstün yeteneklilerin eğitimi alanındaki eğitimciler de nadiren engellerin potansiyelin büyümesini nasıl engelleyebileceğini anlamak için eğitilmektirler. Bu durum öğrenme güçlüğü olan üstün yeteneklilerin tanılamasında ilk zorluk olarak karşımıza çıkmaktadır.

Amerika Birleşik Devletleri'nde 360.000'den fazla iki kere özel çocuğun okula gittiği tahmin edilmektedir (National Education Association, 2006). Türkiye'de iki kere özel öğrenciler için henüz yapılmış bir istatistik çalışması bulunmamaktadır. Türkiye'de öğretmenlere yönelik yapılan çalışmalarda (Altun ve Uzuner, 2016; Başar ve Göncü, 2017; Fırat ve Koçak, 2018), öğrenme güçlüğüne ilişkin öğretmenlerin yetersiz bilgiye sahip oldukları tespit edilmiştir. Aynı sonuç üstün yetenekli çocuklar için de yapılan çalışmalarda benzerlik göstermektedir (Bildiren, 2018b; Şahin ve Kargın, 
2013). Öğretmenlerin öğrenme güçlüğü olan üstün yeteneklilere ilişkin bilgilerinin de yetersiz olabileceği olası gözükmektedir. Muhtemelen bu durum öğrenme güçlüğü olan üstün yetenekli çocukların tanılanmasını da olumsuz etkilemektedir. Tanılama için öğretmenlere yönelik öğrenme güçlügü olan üstün yetenekli çocukların özelliklerine ilişkin hizmetiçi eğitim verilmesinin yararlı olabileceği söylenebilir.

Tanılama için öğretmenlerinin bilgi düzeylerini arttırmak tek başına yararlı olmayacaktır. Öğrenme güçlüğü olan üstün yetenekli öğrencilerin tanılama güçlüğünden dolayı bu öğrenciler yanlış tanılanabilmektedir. Silverman (2005) bunun nedenini beş farklı nedene bağlamaktadır. Bunlardan ilki, öğrenme güçlüğü olan üstün yetenekli öğrencilerin puanlarının ortalaması alınarak hem güçlü hem de zayıf yönlerinin maskelenmesidir. Bir diğer nedeni, kendi güçlü yönleri yerine ortalama çocukların normlarıyla karşılaştırılmasıdır. Ayrıca bu öğrencilerin düşük puanları normların önemli ölçüde altında olmayabilir. Bununla birlikte telafi etme yetenekleri ile puanları artabilir. Güçlü ve zayıf yönleri arasındaki eşitsizliklerin boyutu tam olarak dikkate alınmaz. Bu nedenlerden dolayı tanılama öncesinde birçok entelektüel üstünlüğü ve akademik yeteneği, çeşitli öğrenme güçlüğü biçimleriyle birlikte temsil eden çok heterojen bir öğrenci grubuyla karşılaşabileceğimizi dikkate almamız gerekebilir.

Bazı araştırmacılar, birçok öğrenme güçlüğü olan üstün yetenekli öğrencinin tanılanamadığına inanmaktadır (Brody ve Mills, 1997; Foley Nicpon vd., 2011; Reis vd., 2014). Bu düşünce Türkiye için de söylenebilir. Çünkü ele alabileceğimiz herhangi bir istatistiki veri bulunmamaktadır. Ancak öğrenme güçlügü olan üstün yetenekli öğrencilerin doğru tanımlanması, bu tür öğrencilerin gelişimi için kritik kabul edilir çünkü bu öğrenciler, olumsuz eğitim deneyimleri ve olumsuz motivasyonel, psikolojik ve akademik sonuçlar için bir risk olabilir (Assouline vd., 2010; Besnoy vd., 2015).

Alan yazında savunulan başarı ve zeka düzeyi arasındaki tutarsızlık yaklaşımı, birden çok ölçme aracının kullanılması, müdahale tepki yöntemi (Brody ve Mills, 1997; McCoach vd., 2001, 2013; Nielsen 2002; Yssel vd., 2014) Türkiye'de de uygulanabilir. Her yaklaşımın avantaj ve dezavantajları olabileceği dikkate alındığında bütünleştirilmiş bir tanılama modeli uygulanabilir. Tutarsızlık yaklaşımı, öğrencinin üstün yeteneğinden kaynaklı başarısızlık maskelenebileceği için (Reis vd., 2014) her öğrenci için uygun olmayabilir. Farklı bir durum müdahaleye tepki yönteminde de karşımıza çıkabilir. Öğrenme güçlüğü olan üstün yetenekli öğrenciler, ortalama yetenekli akranlarından daha yüksek akademik potansiyel sergileme eğilimindedir ve bu nedenle özel eğitim uygunluk testine sevk 
edilme olasılıkları daha düşüktür (Brody ve Mills, 1997). Aynı zamanda, çocuğun güçlük yaşadığı alanlar üstün yeteneği maskeleyebilir (Baum, 1990). Bir öğrencinin üstün entelektüiel yetenekleri öğrenme becerilerini maskeleyebileceğinden ve bunun tersi de geçerli olduğundan, üstünlüğü olan pek çok öğrenci ortalama becerilere ve başarıya sahip gibi görünür (McCoach vd., 2001). Öğrencinin öğrenme güçlüğü baskın ise bu durumda da güçlüğe yönelik müdahale uygulanacağından, yetenek alanları göz ardı edilebilir. Bu durumda hem üstün yeteneğin hem de öğrenme güçlüğünün tanılanması daha az olasıdır. Üstün yetenekli öğrencilerin belirlenmesinde bir müdahaleye tepki yönteminin faydasını artırmak için, sınıf üstü düzeydeki tarama araçları da tanılama uygulamalarına dahil edilmelidir (Brown ve Abernethy, 2009). Sonuç olarak öğrencinin güçlü ve zayıf yönlerini aynı anda (Gilman vd., 2013) inceleyen entegre ve bireysel odaklı bir süreç olarak tanılamanın ele alınması önerilebilir.

Tanılama tamamlandıktan sonra önemli bir diğer nokta bu öğrencilerin eğitimleridir. Öğrenme güçlüğü olan üstün yetenekli öğrenciler iki kere özel olarak doğru tanılanırsa, yeteneklerini ve güçlüklerini aynı anda desteklemek için iki kat farklılaştırılmış müfredat alırlarsa daha iyi sonuçlar elde edebilirler (Baum ve Novak, 2010; National Association for Gifted Children, 2013; Nielsen ve Higgins, 2005). Ancak özellikle geç tanılanmalarından dolayı (National Association for Gifted Children, 2013; Reis, Baum ve Burke, 2014), bu durum her zaman gerçekleşemeyebilir. Öğrenme güçlüğü olan öğrenciler için en önemli nokta, karmaşık materyallerin, yaratıcı problem çözme aktivitelerinin ve probleme dayalı öğrenmenin bir araya getirilmesi yoluyla hem üstün yeteneklilik hem de akademik ihtiyaçların ele alınacağı şekilde öğretimi farklılaştırmaktır. (Nielsen ve Higgins, 2005; Pereles, Omdal ve Baldwin, 2009). Özellikle eğitime karşı motivasyonu arttırmak için öğrencilerin ilgi alanlarının kullanılması önerilmektedir (Schanding ve Elmore, 2015).

Öğrenme güçlüğü olan üstün yetenekli öğrenciler, üst düzey akıl yürütme ve problem çözme becerileri, gelişmiş fikirler ve karmaşık konular hakkında içgörüler sergilerler (Nielsen ve Higgins, 2005). Bu nedenle bu öğrenciler için güçlük çektiği alanlar desteklenirken, öğrencilerin güçlü yönlerine odaklanan öğretime erişime fursat verecek öğretim programları uygulanmalıdır (Weinfeld, Barnes-Robinson, Jeweler ve Shevitz, 2005). Öğrencinin güçlü yönlerine odaklanmak, öğrenciye içeriğe ileri düzeyde erişmek için üst düzey işlemleme becerilerini kullanma fursatları sağlar. 2020/2 Böylece öğrenme güçlüğü olan üstün yetenekli öğrenciler var olan performanslarının farkına varabilir ve geliştirebilir. 

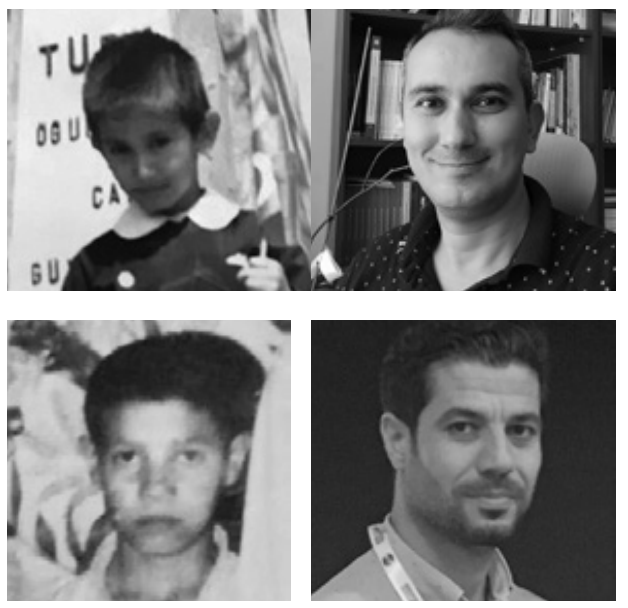

Ahmet Bildiren

Tahsin Fırat

\section{Kaynakça}

Alsop, G. (2003). Asynchrony: Intuitively valid and theoretically reliable. Roeper Review, 25(3), 118127.

Altun, T., ve Uzuner, F. G. (2016). Sınıf öğretmenlerinin özel öğrenme güçlüğü olan öğrencilerin eḡitimine yönelik görüșleri, The Journal of Academic Social Science Studies, 44(33-49).

American Psychiatric Association. (2013). Diagnostic and statistical manual of mental disorders (5th ed.). Arlington, VA: Author.

Assouline, S. G., Foley Nicpon, M., ve Whiteman, C. (2010). Cognitive and psychosocial characteristics of gifted students with written language disability. Gifted Child Quarterly, 54, 102-115.

Baldwin, L., Omdal, S. N., ve Pereles, D. (2015). Beyond stereotypes: Understanding, recognizing, and working with twice-exceptional learners. Teaching Exceptional Children, 47(4), 216-225.

Bașar, M., \& Göncü, A. (2018). Sınıf ögretmenlerinin öğrenme güçlüg̈üyle ilgili kavram yanılgılarının giderilmesi ve ögretmen görüșlerinin deḡerlendirilmesi. Hacettepe Üniversitesi Eḡitim Fakültesi Dergisi, 33(1), 185-206.

Baum, S. (1990). The gifted/learning disabled: A paradox for teachers. from preventing school failure. The Education Digest 55(8), 54-56.

Baum. S. M. (1990). Gifted but learning disabled: A puzzling paradox. Retrieved on April 30, 2020, http://www.hoagiesgifted.org/eric/e479.html

Baum, S., ve Novak, C. (2010). Why isn't talent development on the IEP? SEM and the twice exceptional learner. Gifted Education International, 26, 249-260.

Beckmann, E., ve Minnaert, A. (2018). Non-cognitive characteristics of gifted students with learning disabilities: An in-depth systematic review. Frontiers in Psychology, 9, 504. https://doi. org/10.3389/fpsyg.2018.00504

Berninger, V. W. (2006). Research-supported ideas for implementing reauthorized IDEA with intelligent professional psychological services. Psychology in the Schools, 43(7), 781-796.

Berninger, V., ve Swanson, H. L. (2013). Diagnosing and treating specific learning disabilities in reference to the brain's working memory system. In H. L. Swanson, K. R. Harris, ve S. Graham (Eds.), Handbook of learning disabilities (2nd ed., pp. 169-185). New York: Guilford Press.

Besnoy, K. D., Swoszowski, N. C., Newman, J. L., Floyd, A., Jones, P., ve Byrne, C. (2015). The advocacy experiences of parents of elementary age, twice-exceptional children. Gifted Child Quarterly, 59, 108-123.

Bianco, M., ve Leech, N. L. (2010). Twice-exceptional learners: Effects of teacher preparation and disability labels on gifted referrals. Teacher Education and Special Education, 33(4), 319-334. 
Bildiren, A. (2018a). Developmental characteristics of gifted children aged 0-6 years: parental observations. Early Child Development and Care, 188(8), 997-1011.

Bildiren, A. (2018b). Opinions of primary school teachers on the definition, identification and education of gifted children. International Journal of Eurasia Social Sciences, 9(33), 1363-1380.

Bildiren, A., ve Fırat, T. (2020). Giftedness or disability? Living with paradox. Education 3-13, 48(6), 746-760.

Bisland, A. (2004). Using learning-strategies instruction with students who are gifted and learning disabled. Gifted Child Today, 27(3), 52-58.

Boyle, J. R., Rosen, S. M., ve Forchelli, G. (2016). Exploring metacognitive strategy use during notetaking for students with learning disabilities. Education 3-13, 44(2), 161-180.

Brody, L. E., ve Mills, C. J. (1997). Gifted children with learning disabilities: A review of the issues. Journal of Learning Disabilities, 30(3), 282-296.

Brown, E. F., ve Abernethy, S. H. (2009). Policy implications at the state and district level with RTI for gifted students. Gifted Child Today, 32(3), 52 - 57.

Bryan, T., Burstein, K., ve Ergul, C. (2004). The social-emotional side of learning disabilities: A sciencebased presentation of the state of the art. Learning Disability Quarterly, 27(1), 45-51.

Büttner, G., ve Hasselhorn, M. (2011). Learning disabilities: Debates on definitions, causes, subtypes, and responses. International Journal of Disability, Development and Education, 58(1), 75-87.

Coleman, M. R. (2005). Academic strategies that work for gifted students with learning disabilities. Teaching Exceptional Children, 38, 28-32.

Cornoldi, C., Giofre, D., Orsini, A., ve Pezzuti, L. (2014). Differences in the intellectual profile of children with intellectual vs. learning disability. Research in Developmental Disabilities, 35(9), 2224-2230.

Cakıroḡlu, O. (2017). Öḡrenme güçlüḡü olan çocuklarin genel özellikleri. M. A. Melekoḡlu ve O. Cakiroğlu (Ed). Özel öğrenme güçlüğü olan çocuklar (ss. 49-73). Ankara: Vize Yayıncılık.

Daniels, S., ve Piechowski, M. (2009). Living with intensity: emotional development of gifted children, adolescents, and adults. Tucson, AZ: Great Potential Press.

Dole, S. F. (1999). Identity formation in college students with giftedness and learning disabilities. Unpublished doctoral dissertation (Doctoral Dissertation). Available from ProQuest Dissertations and Theses database. (UMI No. 9949493).

Fırat, T (2019). Öḡrenme güçlüḡü olan üstün yetenekli çocuklara yönelik okulöncesi öḡretmenlerinin görüșleri, I. Uluslararası Katılımlı Özgül Öḡrenme Güçlüḡü Kongresi, İstanbul Ticaret Üniversitesi, İstanbul.

Fırat, T., ve Koçak, D. (2018). Sınıf öğretmenlerinin öğrenme güçlügünün tanımına ilișkin görüșleri. Abant İzet Baysal Üniversitesi Eḡitim Fakültesi Dergisi, 18(2), 915-931.

Fırat, T., ve Koçak, D. (2019). Bașarılı okuyucular ile öğrenme güçlüḡü olan öğrencilerin metni anlamak için kullandıkları bilișsel ve üstbilișsel stratejiler. Kastamonu Eğitim Dergisi, 27(2), 669-681.

Firat, T. (2020). A Multi-Way intervention to improve the social acceptance of a student with learning disabilities. International Journal of Progressive Education, 16(2), 123-136.

Fletcher, J. M., Lyon, G. R., Fuchs, L. S., ve Barnes, M. A. (2018). Learning disabilities: From identification to intervention. Guilford Publications.

Foley Nicpon, M., Allmon, A., Sieck, B., ve Stinson, R. D. (2011). Empirical investigation of twiceexceptionality: Where have we been and where are we going? Gifted Child Quarterly, 55(1), 3-17.

Foley Nicpon M, Assouline S. G. (2020). High ability students with coexisting disabilities: Implications for school psychological practice. Psychol Schs. 1-12. https://doi.org/10.1002/pits.22342

Forness, S. R., ve Kavale, K. A. (1996). Treating social skill deficits in children with learning disabilities: A meta-analysis of the research. Learning Disability Quarterly, 19(1), 2-13.

Fuchs, L. S., ve Fuchs, D. (2001). Helping teachers formulate sound test accommodation decisions for students with learning disabilities. Learning Disabilities Research ve Practice, 16(3), 174-181.

Çocuk ve Medeniyet 2020/2

Gagne, F. (2005). From gifts to talents: The DMGT as a developmental model. In R.J. Sternberg ve J.E. Davidson (Eds.), Conceptions of giftedness (2nd ed.) (98-119). New York: Cambridge University Press.

İki Kere Özel Öğrenciler: Öğrenme Güçlüğü Olan Üstün Yetenekliler 
Gardner, H. (2011). Frames of mind: The theory of multiple intelligences.Ney York: A member of Perseus Book Group.

Geake, J. G. (2008). High abilities at fluid analogizing: A cognitive neuroscience construct of giftedness. Roeper Review, 30, 187-195.

Gilman, B. J., Lovecky, D. V., Kearney, K., Peters, D. B., Wasserman, J. D., Silverman, L. K., . . Rimm, S. B. (2013). Critical issues in the identification of gifted students with coexisting disabilities: The twice-excpeptional. SAGE Open, 3(3). doi:10.1177/2158244013505855

Gross, M. (2003). Exceptionally gifted children. London: Routledge.

Gross, M. U. (2006). Exceptionally gifted children: Long-term outcomes of academic acceleration and nonacceleration. Journal for the Education of the Gifted, 29(4), 404-429.

Heiman, T., ve Precel, K. (2003). Students with learning disabilities in higher education: Academic strategies profile. Journal of Learning Disabilities, 36(3), 248-258.

Handwerk, M. L., ve Marshall, R. M. (1998). Behavioral and emotional problems of students with learning disabilities, serious emotional disturbance, or both conditions. Journal of Learning Disabilities, 31(4), 327-338.

Huntington, D. D., ve Bender, W. N. (1993). Adolescents with learning disabilities at risk? Emotional well-being, depression, suicide. Journal of Learning Disabilities, 26(3), 159-166.

Individuals with Disabilities Education Act of (IDEA) 2004. 20 U. S. C. §1400 et seq. (2004).

Kanevsky, L. S. (1990). Pursuing qualitative differences in the flexible use of problem-solving strategy by young children. Journal for the Education of the Gifted, 13, 115-140.

Kavale, K. A., ve Mostert, M. P. (2004). Social skills interventions for individuals with learning disabilities. Learning Disability Quarterly, 27(1), 31-43.

Kavale, K. A., ve Spaulding, L. S. (2008). Is response to intervention good policy for specific learning disability? Learning Disabilities Research ve Practice, 23(4), 169 - 179.

Klavir, R., ve Gorodetsky, M. (2001). The Processing of analogous problems in the verbal and visualhumorous (Cartoons) modalities by gifted/average children. Gifted Child Quarterly, 45, 205-215.

King, E. W. (2005). Addressing the social and emotional needs of twice-exceptional students. Teaching Exceptional Children, 38(1), 16-21.

Lovett, B. J., ve Sparks, R. L. (2013). The identification and performance of gifted students with learning disability diagnoses: A quantitative synthesis. Journal of Learning Disabilities, 46, 304316.

Mayes, S. D., ve Calhoun, S. L. (2006). Frequency of reading, math, and writing disabilities in children with clinical disorders. Learning and Individual Differences, 16(2), 145-157.

McCoach, D. B., Kehle, T. J., Bray, M. A., ve Siegle, D. (2001). Best practices in the identification of gifted students with learning disabilities. Psychology in the Schools, 38(5), 403-411.

McCallum, R. S., S. M. Bell, J. T. Coles, K. C. Miller, M. B. Hopkins, and A. Hilton-Prillhart. 2013. A model for screening twiceexceptional students (Gifted with learning disabilities) within a response to Intervention paradigm. Gifted Child Quarterly 57(4), 209-222.

McFarland, J., Hussar, B., Zhang, J., Wang, X., Wang, K., Hein, S., Diliberti, M., Forrest Cataldi, E., Bullock Mann, F., ve Barmer, A. (2019). The condition of education 2019 (NCES-144). Washington, DC: National Center for Education Statistics.

McNamara, J. K., ve Wong, B. (2003). Memory for everyday information in students with learning disabilities. Journal of Learning Disabilities, 36(5), 394-406.

Melekoglu, M. A. (2011). Impact of motivation to read on reading gains for struggling readers with and without learning disabilities. Learning Disability Quarterly, 34(4), 248-261.

Melekoḡlu, M. A. (2017). Özel öğrenme güçlüḡüne giriș. M. A. Melekoḡlu ve O. Çakıroḡlu (Ed.), Özel ögrenme güçlügü olan çocuklar, (s. 15-47). Ankara: Vize Yayıncılık.

Çocuk ve Medeniyet 2020/2
Morelock, M. J. (1992). Giftedness: The view from within. Understanding Our Gifted, 4(3), 11-15.

National Education Association. (2006). The twice-exceptional dilemma. Washington, DC: Author. http://www.nagc.org/sites/default/files/key\%20reports/twiceexceptional.pdf 
National Association for Gifted Children. (2013). Ensuring gifted children with disabilities receive appropriate services: Call for comprehensive assessment. https://www.nagc.org/sites/default/ files/Position\%20Statement/Ensuring\%20Gifted\%20Children\%20with\%20Disabilities\%20 Receive\%20Appropriate\%20Services.pdf

Navas Snchez, F. J., Alemán Gómez, Y., Sánchez-González, J., Guzmán De Villoria, J. A., Franco, C., Robles, O., ... ve Desco, M. (2014). White matter microstructure correlates of mathematical giftedness and intelligence quotient. Human Brain Mapping, 35(6), 2619-2631.

Navas Sánchez, F. J., Carmona, S., Alemán Gómez, Y., Sánchez-González, J., Guzmán de Villoria, J., Franco, C., ... ve Desco, M. (2016). Cortical morphometry in frontoparietal and default mode networks in math gifted adolescents. Human Brain Mapping, 37(5), 1893-1902.

Nielsen, M. E. (2002). Gifted students with learning disabilities: Recommendations for identification and programming. Exceptionality, 10, 93-111

Nielsen, M. E., ve Higgins, L. D. (2005). The eye of the storm: Services and programs for twiceexceptional learners. Teaching Exceptional Children, 38, 8-15.

Neihart, M. (2008). Identifying and providing services to twice exceptional children. In Handbook of giftedness in children (pp. 115-137). Springer, Boston, MA.

Özmen, R. G. (2008). Öḡrenme Güçlüḡü Olan Öḡrenciler. Diken, İ. H. (Ed.) Özel Eḡitime Gereksinimi Olan Öğrenciler ve Özel Eğitim (s. 335-366). Ankara: Pegem Akademi Yayınları.

Park, J. P. (2010). Learning disabilities: diseases and disorders. San Diego: ReferencePoint Press, Inc.

Pastor, P. N., ve Reuben, C. A. (2008). Diagnosed attention deficit hyperactivity disorder and learning disability: United States, 2004-2006. Vital and Health Statistics. Series 10, Data from the National Health Survey, (237), 1-14.

Pereles, D. A., Omdal, S., ve Baldwin, L. (2009). Response to intervention and twice-exceptional learners: A promising fit. Gifted Child Today, 32, 40-51. doi:10.1177/ 107621750903200310

Piechowski, M. M., ve Chucker, J. (2011). Overexcitabilities. Encyclopedia of Creativity, 2, 202-208.

Pierangelo, R., ve Giuliani, G. (2008). Teaching students with learning disabilities: A step-by-step guide for educators. Corwin Press.

Reis, S. M., Baum, S. M., and Burke, E. (2014). An operational definition of twice-exceptional learners: Implications and applications. Gifted Child Q. 58, 217-230.

Renzulli, J.S. (2005). The three-ring conception of giftedness: A developmental model for promoting creative productivity. In R.J. Sternberg ve J. Davidson (Eds.), Conceptions of giftedness (2nd ed.) (217-279). Boston: Cambridge University Press.

Robinson, S. M. (1999). Meeting the needs of students who are gifted and have learning disabilities. Intervention in School and Clinic, 34(4), 195-204.

Ruban, L. M., Reis, S.M. (2005). Identification and assessment of gifted students with learning disabilities. Theory into Practice, 44(2), 115-124.

Ruban, L. M. (2005). Identification and assessment of gifted students with learning disabilities. Theory into Practice, 44(2), 115-124.

Sak, U. (2017). Üstün zekalılar. Ankara: Vize Yayıncılık.

Sansom, S. (2015). Gifted students with learning disabilities: A current review of the literature. Acta Scientiae et Intellectus, 1(1), 5-17.

Sideridis, G. D., Morgan, P. L., Botsas, G., Padeliadu, S., ve Fuchs, D. (2006). Predicting LD on the basis of motivation, metacognition, and psychopathology: An ROC analysis. Journal of Learning Disabilities, 39(3), 215-229.

Silverman, L. K. (2003). Gifted children with learning disabilities. In N. A. Colangelo ve G. A. Davis (Eds.), Handbook of gifted education (3rd ed., pp. 533-543). Boston: Allyn ve Bacon

Silverman, L. (2005). The two-edged sword of compensation: How the gifted cope with learning disabilities. In K. Kay (Ed.) (2000). Uniquely gifted: Identifying and meeting the needs of twice exceptional learners (pp. 153-165). Gilsum, NH: Avocus Publishing.

Çocuk ve Medeniyet 2020/2
Swanson, L., Harris, K. R., ve Graham, S. (2013). Handbook of learning disabilities (2nd ed.). New York, NY: Guilford.

İki Kere Özel Öğrenciler: Öğrenme Güçlüğü Olan Üstün Yetenekliler 
Şahin, F., ve Kargın, T. (2013). Sını öḡretmenlerine üstün yetenekli öḡrencilerin belirlenmesi konusunda verilen bir eḡitim programının etkililiḡi. Ankara Üniversitesi Ē̄itim Bilimleri Fakültesi Özel Eğitim Dergisi, 14(2), 1-23.

Tannenbaum, A. J. (2003) Nature and nurture of giftedness. In Colangelo, N. veDavis,G.A. (Eds.) Handbook of gifted education (3rd edition), 45-59. Boston: Pearson Education.

Tieso, C. L. (2007). Patterns of overexcitabilities in identified gifted students and their parents: a hierarchicalmodel. Gifted Child Quarterly, 51(1), 11-22.

van Viersen, S., Kroesbergen, E. H., Slot, E. M., ve de Bree, E. H. (2016). High reading skills mask dyslexia in gifted children. Journal of Learning Disabilities, 49(2), 189-199.

Vaughn, S., Linan-Thompson, S., ve Hickman, P. (2003). Response to instruction as a means of identifying students with reading/learning disabilities. Exceptional Children, 69(4), 391 - 409.

Walsh, R. L., Hodge, K. A., Bowes, J. M., ve Kemp, C. R. (2010). Same age, different page: Overcoming the barriers to catering for young gifted children in prior-to-school settings. International Journal of Early Childhood, 42(1), 43-58.

Watson, S. M., Gable, R. A., ve Morin, L. L. (2016). The role of executive functions in classroom instruction of students with learning disabilities. International Journal of School and Cognitive Psychology, 3(167), 1-5. doi:10.4172/2469-9837.1000167

Weinfeld, R., Barnes-Robinson, L., Jeweler, S., ve Shevitz, B. R. (2005). What we have learned: Experiences in providing adaptations and accommodations for gifted and talented students with learning disabilities. Teaching Exceptional Children, 38, 48-53.

Wong, B. ve Butter, D. (2012). Learning about learning disabilities. New York: Elsevier Academic Press.

Wright, B. L., ve Ford, D. Y. (2017). Untapped potential: Recognition of giftedness in early childhood and what professionals should know about students of color. Gifted Child Today, 4O(2), 111-116.

Yssel, N., C. Adams, L. S. Clarke, and R. Jones. 2014. Applying an Rtl model for students with learning disabilities who are gifted. Teaching Exceptional Children, 46(3), 42-52.

Zhang, L., Gan, J. Q., ve Wang, H. (2017). Neurocognitive mechanisms of mathematical giftedness: A literature review. Applied Neuropsychology: Child, 6(1), 79-94.

Zisimopoulos, D. A., ve Galanaki, E. P. (2009). Academic intrinsic motivation and perceived academic competence in Greek elementary students with and without learning disabilities. Learning Disabilities Research ve Practice, 24(1), 33-43. 